\title{
EL CONCEPTO DE PRÁCTICA EN LA PEDAGOGÍA Y LA DIDÁCTICA
}

\section{Francisco Beltrán Peña*}

"La praxis no es la poiesis":

Aristóteles.

Existen dos tendencias bien acentuadas en la concepción de la Práctica Pedagógica y Didáctica. Entre los seguidores de una u otra sedan serias discrepancias tanto en el fondo como en la forma. Aunque a decir verdad para unos importa más la forma que el fondo, porque en suma se los confunde al identificarlos. El núcleo de la discusión se deriva del significado empírico atribuido al término "práctica", o de la conceptualización de éste. Como puede verse, no se trata de lo mismo.

La tendencia empírica se mueve dentro de la preocupación por los haceres, entendidos como aplicación de ejercicio, habilidad, destreza, costumbre, estilo, método, que no metodología. Su racionalidad, por lo general siempre implícita corresponde con la poiética o productividad. En términos del saber popular responde al adagio: "El todo es hacer compadrito". ¿Qué, porqué, para qué, desde dónde, hacia dónde, con quién, a favor de quién, o en contra de quién? Tales interrogantes parecen no contar. La otra tendencia se centra en el proceso de la interacción personal, la deliberación, la toma de decisiones, la articulación de propuestas dirigidas a la cualificación de quien la formula como de los destinatarios, la relación de ésta con un concepto de pedagogía, educación física y agente de cambio social. Su racionalidad explícita es la de la praxis, práctica o política, entendida ésta como búsqueda del bien común de la sociedad.

La discrepancia existente entre las dos tendencias enunciadas es fácil de resolver si se acude a la lógica (Lógos. racionalidad, explicación sólida, coherente y consecuente), y no a la logomaquia. Se trata, entonces, de conceptualizar a fin de superar la opinión entendida como doxa según Platón-, expresión de sentires y pareceres del sentido común carentes de fundamentación y el impirismo a ultranza. De paso no debe olvidarse que Platón desarmó y descartó la opinión en la vía del conocimiento racional. La opinionitis constituyo el espacio propio de la pereza mental, de la locheidad intelectual y por ende de la ignorancia o hartazgo de errores. El conocimiento racional se desenvuelve mediante la duda, la cual da lugar al cuestionamiento, la formulación de hipótesis y su respectiva búsqueda de respuestas por medio de la observación, análisis, síntesis, estudio, investigación, argumentación, sustentación, crítica y autocrítica. De esta manera el conocimiento racional trabaja con hipótesis, puntos de vista sustentados, teorías sólidas.

El epicentro de la conceptualización aquí requerida radica en el concepto de hombre. ¿Con cuál visión del hombre se aborda el problema en cuestión? Apenas obvio que se descarta cualesquiera dc los conceptos reduccionistas tales como el biologismo, el mecanicismo u otros de carácter dualista. Se asume la concepción sobre la unidad bíopsíquico -socio-cultural-ecológica en camino de su desarrollo humano, que no crecimiento (cuantificación). Esta comprensión implica la superación del pensar al hombre, básicamente, desde su inteligencia teórica, tal como lo hace la filosofía griega y moderna europea. Es de anotar que la razón, la reflexión o la autoconciencia son actos teóricos.

\footnotetext{
${ }^{*}$ Profesor de la U.PN. 
Así que la visión del hombre debe replantearse desde otro horizonte distinto del racionalismo e idealismo. Se trata de asumir la concepción de la alteridad.

La concepción del hombre como alteridad se basa en el reconocimiento del otro y de los otros en el encuentro, a partir de la interrelación, que significa respetar al otro, tomarlo en serio, a fin de interactuar con él para promover el desarrollo humano o cualificación de la vida humana. Su punto de partida es la inteligencia práctica, posibilitadora de inteligencia poiética, y ésta a su vez de inteligencia teórica. El fundamento de esta concepción radica en que "La apertura primera del hombre es práctica y por ello poiética"

(DUSSEL, E.1980, 2.1.3.1;2.1.6; 1.984 p.26). La base está en partir del hecho general más evidente pero a la vez el más desconocido. Se trata de la primera experiencia huma real y efectiva, la experiencia anterior a cualesquiera otra experiencia posible, como lo es la experiencia humana de lo humano, la relación hombre-hombre. "persona-a-persona" el "cara-a-cara", el encuentro con el otro, la proximidad del prójimo. Esta es la experiencia las experiencias, la relación primigenia, fundante, a la vez que fundamental, que genera la vida humana y la impregna a lo largo su proceso hasta la muerte.

El hombre nace en lo humano, no en la naturaleza y sus elementos hostiles, como sí les sucede los animales. El hombre es concebido en una relación humana de encuentro interpersonal cara-a-cara de profunda calidez, aprecio, cariño afecto, entrega recíproca, ternura amor. Esta es la experiencia que informa la concepción, la gestación, el nacimiento, la alimentación, protección, el posterior desarrollo hasta la muerte. El hombre nace lo humano, se alimenta de lo humano y se desenvuelve dentro de lo humano. Toda la relacionalidad del hombre se inscribe necesariamente dentro de lo humano en primera instancia, y tan sólo a partir de ésta puede acceder a la relación con la naturaleza: inteligencia poiética

La experiencia primera del hombre es la relación con el hombre en su proximidad. Esta es la relación práctica. Práctica viene de la palabra griega praxis que significa acción, obra. Praxis es "el acto que se dirige a otra persona humana; acto hacia otra persona y relación misma de persona a persona. Praxis es un "acto" que efectúa una persona, un sujeto humano, pero que se dirige directamente a otra persona (un apretón de manos, un beso, un diálogo, un golpe), o indirectamente (por intermedio de algo: por ejemplo, repartir un pedazo de pan; el pan no es persona, pero se reparte a la otra persona). Si estoy dormido no estoy presente en el mundo porque descanso, porque no estoy consciente: no hay praxis entonces. La praxis es la manera actual de estar en nuestro mundo ante otro; es la presencia real de una persona ante otra. Praxis es la "relación" misma de dos o más personas, la relación práctica entre personas es la praxis" (DUSSEL,1986,p. 16).

"La praxis no es la poiesis", afirma Aristóteles. No se puede por ningún motivo, bajo ningún pretexto confundir la práctica con la poiética. Sería tanto como confundir el agua con el aceite. Se trata de dos relaciones distintas, más no antagónicas, ya que la poiesis depende de la praxis, y esto es muy importante. La praxis o relación humana es la mediadora de la relación con la naturaleza. Es decir, cl hombre se relaciona con la naturaleza gracias a la relación con el mismo hombre.

Praxis significa operar (operare), obrar con y en otro u otros. En cambio poiesis significa fabricar, hacer (facere), producir con o en algo, trabajar la naturaleza. La poiesis es la relación hombre-naturaleza. La relación de trabajo "persona-naturaleza -producto" es una acción productiva, fabricativa, trabajo. 
El ser humano obra, actúa, se relaciona con otros y conjuntamente con ellos hace, realiza, produce. ¿Por qué? ¿Para qué? Simplemente para poder ser, que es el proyecto; "lo-queno-se-es-todavía" me interpreta, me hiere como"falta-de". Por ello la praxis, el obrar en otros y con otros, me permite completar cuanto me falta. "Praxis es la acción exigida por la "falta de" en mi proyecto, pero es mucho más. Praxis es la actualidad misma del ser en el mundo. Es decir, siempre estamos en praxis. La actitud práctica es nuestra actitud cotidiana" (DUSSEL,1995,p.75, 106). Es más, "La praxis es la acción u operación humana, fundamentalmente política" DUSSEL,1984, p,39). Para Aristóteles "La ciencia política es la arquitectónica" (Et. Nic. A. 1, 1094 a 28), entendida como la última instancia a la que se subordina lo demás en función del bien humano en general. La praxis es política porque delibera sobre cuanto se ha de elegir en relación con la sociedad, comunidad o grupo humano. Así que praxis, política y ética se interrelacionan entre sí. "Conciencia ética es el saber "abrirse" al otro y tomarlo a cargo (responsabilidad) por el otro ante el sistema” (DUSSEL, 1986, p.49-50).

En aras de posibilitar síntesis unas preguntas. ¿Qué se entiende por Educación Física? ¿,Se trata de un oficio y por ende de una técnica, un arte, una profesión, una disciplina? Si su nombre es Educación Física, ¿significa que forma parte de la disciplina educación? ¿Qué se entiende, entonces, por educación'? ¿Qué relación existe entre educación y pedagogía? ¿La pedagogía se la puede reducir a la didáctica? ¿Cuál es la relación entre pedagogía y didáctica? ¿Cómo se ha entendido y asumido la práctica? ¿La práctica es cuestión de haceres, y por ende de procedimientos, o por el contrario es asunto de praxis? ¿Qué elementos teóricos aporta el presente artículo al esclarecimiento de la comprensión de la "Práctica"?

DUSSEL, 1980: Filosofía de la liberación, USTA, Bogotá;

1984: Filosofía de la producción,

Nueva América, Bogotá;

1986: Ética comunitaria, Paulinas, Madrid.

1995: Introducción ala filosofía de la liberación, Nueva América, Bogotá, 5a. 